\title{
CHARACTERIZATION OF TEN MICROSATELLITE LOCI IN THE BLUE MUSSEL MYTILUS EDULIS
}

\author{
DELPHINE LALLIAS, ${ }^{1 *}$ RUTH STOCKDALE, ${ }^{1}$ PIERRE BOUDRY,${ }^{2}$ SYLVIE LAPÈGUE ${ }^{3}$ \\ AND ANDY R. BEAUMONT ${ }^{\mathbf{1}}$ \\ ${ }^{1}$ School of Ocean Sciences, Center for Applied Marine Sciences, College of Natural Sciences, Bangor \\ University, Menai Bridge, Gwynedd, LL59 5 AB, United Kingdom; ${ }^{2}$ Ifremer, UMR M100 Physiologie et \\ Ecophysiologie des Mollusques Marins, Plouzané, France, ${ }^{3}$ Ifremer, Laboratoire Génétique et Pathologie, \\ Ronce-les-bains, 17390 La Tremblade, France
}

\begin{abstract}
Mussels of the genus Mytilus are ecologically and commercially important worldwide, and they form hybrid complexes where their distributions overlap. Allozyme and nuclear markers have been used to investigate their genetics over many years, but successful development of reliable highly valuable microsatellite markers has lagged behind other shellfish species. We have developed and characterized ten novel microsatellite loci that amplify reliably for the blue mussel Mytilus edulis. The number of alleles among 30 individuals from a wild population (Menai Strait, North Wales, UK) ranged between 9 and 29 and the observed heterozygosity between 0.300 and 0.954 . Significant heterozygote deficiencies against the Hardy-Weinberg model were observed at 6 out of 10 loci. Analyses using MICRO-CHECKER suggested the presence of null alleles at 8 out of 10 microsatellites with estimated null allele frequencies ranging from $0.105-0.305$. The 10 newly developed microsatellites will have value to discriminate between Mytilus species, to support studies of introgression and hybridization and to strengthen and improve the available genetic linkage map.
\end{abstract}

KEY WORDS: Mytilus edulis, microsatellites, universal tailed-primer labeling, null alleles, mussels

\section{INTRODUCTION}

Mussels of the genus Mytilus are ecologically important as members of inter and subtidal communities. Mussels are also farmed on suspended ropes (rafts or long-line), bouchots or by sea-bed culture and are commercially important with a worldwide annual production of $1.8 \mathrm{mt}$ (Spencer 2002, FAO 2006). Three species, Mytilus edulis (Linnaeus, 1758), M. galloprovincialis (Lamarck, 1819) and M. trossulus (Gould, 1850), are very closely related and form hybrid complexes where their distributions overlap. There remains uncertainty about the specific status of these mussel taxa, but it is convenient to refer to them as species (Koehn 1991, Gosling 1992, Riginos \& Cunningham 2005). The current view is that $M$. trossulus originated from the Pacific Ocean and has probably twice colonized the northern Atlantic via the Bering Strait (Riginos \& Cunningham 2005). The first invasion produced Atlantic $M$. edulis by allopatric speciation whereas $M$. galloprovincialis evolved separately in the Mediterranean when it lost connection with the Atlantic (Vermeij 1991, Riginos \& Cunningham 2005). The M. trossulustype mussels in the Atlantic region (Canada, Baltic, Scotland) probably came from the second invasion of Pacific mussels (Riginos \& Cunningham 2005, Beaumont et al. 2008). Southern hemisphere Mytilus spp. probably arose from natural and anthropogenic transequatorial migrations (Hilbish et al. 2000, Borsa et al. 2007, Gérard et al. 2008).

Blue mussels taxonomy and worldwide distribution was explored and clarified using shell morphometrics and allozyme genetic markers by McDonald et al. (1991), and since that time a variety of DNA-based markers have been developed. None of the allozyme markers used were diagnostic for any of the three species (Gosling 1992), but several nuclear DNA markers are considered diagnostic between pairs of species in different areas of the world e.g., ITS (Heath et al. 1995); Me15/16 (Inoue et al.

*Corresponding author: E-mail: d.lallias@bangor.ac.uk
1995); Glu-5' (Rawson et al. 1996); MAL-1 (Rawson et al. 2001) and EFbis (Bierne et al. 2003c).

Microsatellite loci are commonly used to explore the genetics of closely related species and would be of great value in the study of mussels because of their rapid evolution, codominant Mendelian inheritance, high polymorphism, and presumed neutrality. They are also very useful codominant markers for use in genetic mapping and could strengthen the recently developed AFLP-based M. edulis linkage map (Lallias et al. 2007). In spite of their usefulness, few reliable microsatellite markers have so far been published for mussels and none have been developed specifically from $M$. edulis DNA. Seventeen microsatellite loci are reported for $M$. galloprovincialis (Presa et al. 2002 (7 loci); Varela et al. 2007 (2 loci); Yu \& Li 2007 (8 loci)) and six microsatellites for $M$. trossulus, of which four are reported to cross-amplify with $M$. edulis (Gardeström et al. 2008). Presa et al. (2002) reported M. edulis and M. trossulus cross-species amplification with all 7 of their M. galloprovincialis microsatellites. However, the Presa et al. (2002) microsatellites do not seem to reliably amplify in $M$. edulis in other laboratories (A. Hamilton, pers. comm.) nor are they reliably amplified in $M$. trossulus (Gardeström et al. 2008). Nevertheless, 6 of the Presa et al. (2002) microsatellites have been successfully used to investigate population structure of $M$. galloprovincialis around the Iberian Peninsula (Diz \& Presa 2008). Here we report the development of ten novel microsatellite markers that consistently and reliably amplify for $M$. edulis.

\section{MATERIALS AND METHODS}

M. edulis were collected from the Menai Strait, Irish Sea, a region from which other mussel species have never been reported (Skibinski et al. 1983, Gosling et al. 2008), and DNA was extracted from adult gills.

An enriched library was made by ecogenics $\mathrm{GmbH}$ (Zurich, Switzerland) from size selected genomic DNA ligated into SNX 
forward/SNX reverselinker (Hamilton et al. 1999) and enriched by magnetic bead selection with biotin-labeled $(\mathrm{GT})_{13}$ and $(\mathrm{CT})_{13}$ oligonucleotide repeats (Gautschi et al. 2000). Ecogenics provided sequences containing microsatellites and polymerase chain reaction (PCR) primers were designed for those sequences with suitable flanking regions using PRIMER3 (www.genome. wi.mit.edu/cgi-bin/primer/primer3_www.cgi). PCR conditions were initially optimized using a small sample of Menai Strait mussels, by changing the annealing temperature, the primers and $\mathrm{MgCl}_{2}$ concentrations as well as the amplification profiles. Suitable microsatellites were finally typed on a scoring panel of 30 Menai Strait mussels. An economical method using universal fluorescent-labeled tailed primers (Schuelke 2000) was used for the labeling of PCR fragments. The sequences of the four tailed primers used are given in Table 1. Optimal PCR conditions were determined in reactions containing $100 \mathrm{ng}$ genomic DNA, 1X GoTaq $^{\circledR}$ Flexi Buffer (Promega), $1 \mathrm{mM} \mathrm{MgCl}_{2}, 80 \mu \mathrm{M}$ of $\mathrm{dNTP}, 0.02 \mu \mathrm{M}$ of unlabeled forward primer with a tail at the $5^{\prime}$ end, $0.1 \mu \mathrm{M}$ of unlabeled reverse primer, $0.1 \mu \mathrm{M}$ of labeled tail, and $1 \mathrm{U}$ of GoTaq ${ }^{\circledR}$ Flexi DNA Polymerase (Promega) in a $15 \mu \mathrm{L}$ final volume. Amplification was conducted in Mastercycle thermal cyclers (Eppendorf) using an initial denaturation at $96^{\circ} \mathrm{C}$ for $5 \mathrm{~min}$; followed by 12 cycles of $96^{\circ} \mathrm{C}$ for $30 \mathrm{~s}, \mathrm{~T}_{\mathrm{a}}$ (see Table 1) for $1 \mathrm{~min} 30 \mathrm{~s}, 72^{\circ} \mathrm{C}$ for $1 \mathrm{~min}$; followed by 30 cycles of $96^{\circ} \mathrm{C}$ for $30 \mathrm{~s}, 50^{\circ} \mathrm{C}$ (annealing temperature of the universal tailed primers) for $1 \mathrm{~min} 30 \mathrm{~s}, 72^{\circ} \mathrm{C}$ for $1 \mathrm{~min}$; and terminated by a final elongation at $72^{\circ} \mathrm{C}$ for $30 \mathrm{~min}$. Products were visualized on an ABI 3130xl Genetic Analyser using 36-cm capillary arrays with GeneScan 500 LIZ size standard (Applied Biosystems).

Microsatellite data were tested for agreement with the HardyWeinberg model using GENEPOP (Rousset \& Raymond 1995) and for the presence of null alleles and other scoring errors using MICRO-CHECKER (Van Oosterhout et al. 2004).

\section{RESULTS}

Of the 750 recombinant colonies that were screened, 157 gave a positive signal after hybridization (92 GT, 65 CT). Plasmids from these 157 positive clones were sequenced and 76 unique sequences (occurring once) were found. PCR primers were designed for 62 microsatellite inserts that had suitable flanking sequences and PCR conditions were optimized using a sample of 4 mussels on 2\% agarose gel. Successful amplification in all 4 samples was achieved for 40 microsatellite loci that were then further optimized on a test sample of eight mussels on an ABI 3130xl Genetic Analyser. Clear and unambiguous scoring could only be achieved for 10 out of the 40 microsatellite markers and these were finally tested on 30 individuals.

The ten new polymorphic microsatellite markers developed in M. edulis (GenBank Accession numbers FJ174675FJ174684) varied widely in their degree of polymorphism, with the number of alleles $\left(\mathrm{n}_{\mathrm{a}}\right)$ ranging from 9-29 and the observed heterozygosity $\left(\mathrm{H}_{\mathrm{o}}\right)$ from $0.300-0.954$ (Table 1). Exact tests for deviations from Hardy Weinberg equilibrium were performed using GENEPOP and six loci exhibited a significant deficiency of heterozygotes (Table 1) with one possible cause being the presence of null alleles. Analyses using MICRO-CHECKER indicated the likely presence of null alleles at eight of the loci and the estimated null allele frequencies are given in Table 2. The estimated null allele frequencies range from 0.107 up to 0.305. Moreover, four of the loci showed a high estimated null allele frequency together with a highly significant positive $F_{\text {is }}$ (heterozygote deficiency), strongly suggesting a causative relationship.

After correcting allele frequencies for putative null alleles, a significant deviation from linkage equilibrium was detected with GENEPOP for only one pair of loci: Med $362 /$ Med 722 $(P<0.001)$.

\section{DISCUSSION}

Half of the microsatellite loci that we isolated were not pure simple sequence repeats but were interrupted in some way although most were dinucleotides, as expected from using (GT) and (CT) probes. Irrespective of sample size, the numbers of alleles at these loci $\left(\mathrm{n}_{\mathrm{a}}\right.$ range $9-28$ mean $\left.=20.0, n=30\right)$ are greater than those identified in M. galloprovincialis $\left(\mathrm{n}_{\mathrm{a}}\right.$ range 514 , mean $=9.6, n=12-82$, Presa et al. 2002, $\mathrm{n}_{\mathrm{a}}$ range $2-10$, mean $=4.6, n=40 \mathrm{Yu} \& \mathrm{Li} 2007)$ and $M$. trossulus $\left(\mathrm{n}_{\mathrm{a}}\right.$ range $3-$ 13 , mean $=6.3, n=25$ Gardeström et al. 2008). It is not clear why the microsatellites isolated from $M$. edulis should be consistently more variable than those isolated from the other two species. The samples used have all come from wild populations and the selection process of working from an initial 100-200 microsatellite sequences to isolate useable microsatellites was similar in all cases.

Allozyme genetic studies of bivalves have often revealed significant deficiencies of heterozygotes relative to the HardyWeinberg model and a number of explanations were proposed such as selection, the Wahlund effect, inbreeding and null alleles where the presence of nonfunctional protein product confuses the scoring of heterozygotes and homozygotes (Gaffney 1994). Microsatellite loci also often show heterozygote deficiencies in bivalves (McGoldrick et al. 2000, Boudry et al. 2002, Launey et al. 2002, Li et al. 2003, Beaumont et al. 2006). Because it is assumed that microsatellite loci are noncoding, selection is usually ruled out as a cause of deviation from the HardyWeinberg model and null alleles (caused by point mutations in the primer sequences flanking the microsatellite) are regarded as the most likely cause. It is suggested that microsatellite null alleles in bivalves are caused by high nucleotide diversity in the noncoding regions, which is a consequence of huge effective population sizes (Bierne et al. 2003a). In the particular case of mussels, the occurrence of null alleles might also be amplified by the secondary introgression of highly divergent alleles coming from closely related species (Bierne et al. 2003b, Faure et al. 2008). However, the M. edulis used in this study come from a source that, as far as we know, is monospecific and has not been in interbreeding contact with other species in the recent evolutionary past.

Despite the high frequency of null alleles, the 10 newly developed microsatellites will be a valuable addition to the microsatellite loci already developed for $M$. galloprovincialis (Presa et al. 2002, Yu \& Li 2007) and M. trossulus (Gardeström et al. 2008). Simulation studies have shown that the presence of null alleles at microsatellite loci can be safely accommodated in estimation of population differentiation and genetic distances (Chapuis \& Estoup 2007). Further optimization work on all the microsatellite loci for these three species of mussel will enable the development of a suite of loci that can be deployed to look in fine detail at the many hybrid zones between the species. For example previous work using nuclear markers in the 
Ten Novel Microsatellites for Mytilus edUliS

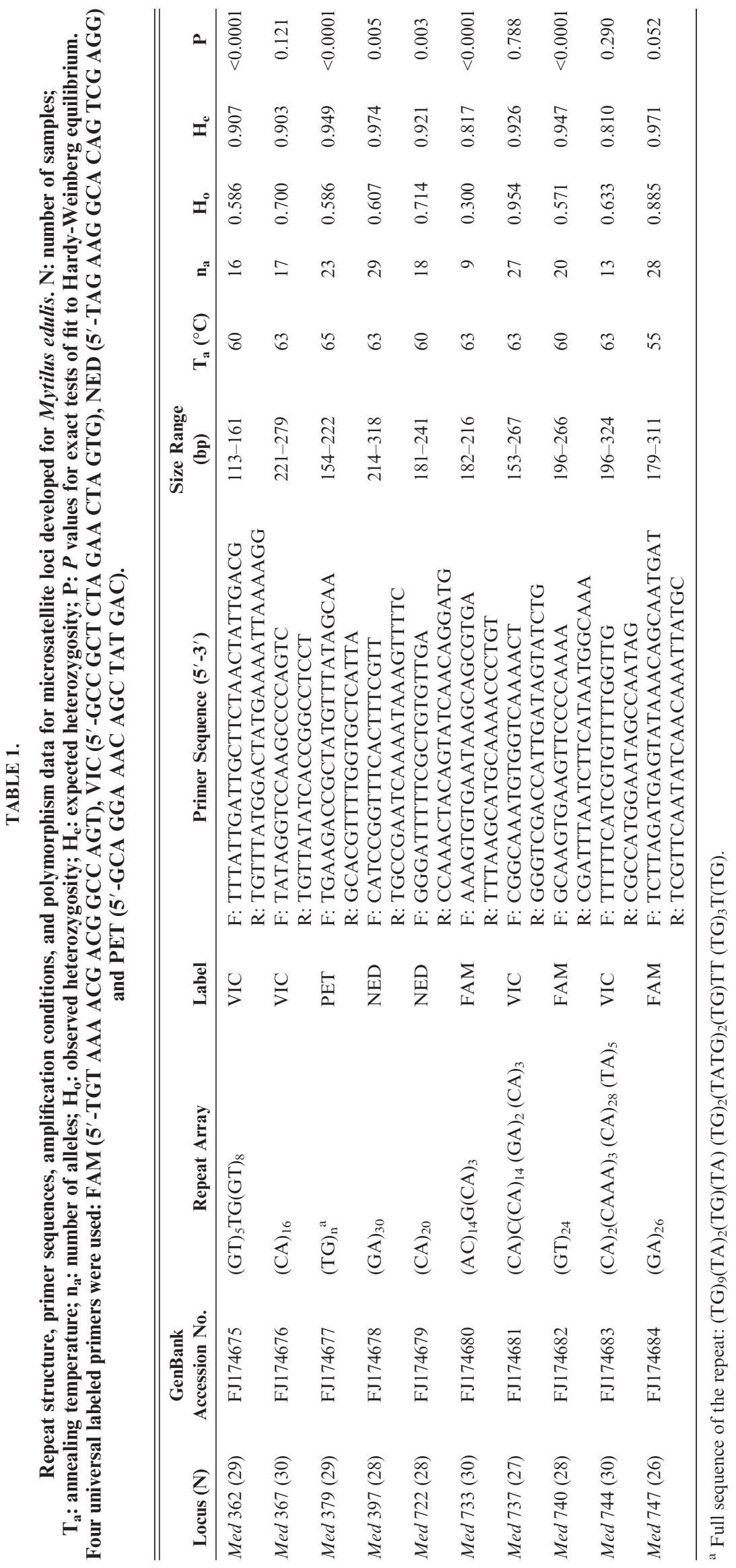


TABLE 2.

Null allele frequencies estimated with MICRO-CHECKER (Van Oosterhout et al. 2004) for eight microsatellite loci in M. edulis. $F_{\text {is }}$ and exact tests of fit to Hardy Weinberg equilibrium from GENEPOP (Rousset \& Raymond 1995). NS: nonsignificant; $*: P<0.05 ; * *: P<0.01 ; * * *: P<0.001$.

\begin{tabular}{lcl}
\hline \hline Locus & $\begin{array}{c}\text { Estimated Frequency } \\
\text { of Null Allele }\end{array}$ & \multicolumn{1}{c}{$\mathbf{F}_{\text {is }}$} \\
\hline Med 362 & 0.170 & $0.358^{* * *}$ \\
Med 367 & 0.107 & $0.228^{\mathrm{NS}}$ \\
Med 379 & 0.186 & $0.387^{* * *}$ \\
Med 397 & 0.182 & $0.381^{* *}$ \\
Med 722 & 0.107 & $0.228^{* *}$ \\
Med 733 & 0.305 & $0.637^{* * *}$ \\
Med 740 & 0.194 & $0.401^{* * *}$ \\
Med 744 & 0.105 & $0.221^{\mathrm{NS}}$ \\
\hline
\end{tabular}

M. edulis/M. galloprovincialis zone around southwest Britain has shown a highly complex interaction between the hydrography of larval transport and differential selection operating on settled juveniles and adults (e.g., Hilbish et al. 2002). The use of highly variable microsatellites will enable a better understand- ing of connectivity between the two species, the fate of hybrids and the hybridization process itself.

Microsatellites are proving increasingly valuable in the management of aquaculture species and although mussel culture is principally of "wild" individuals obtained by natural spatfall, hatchery culture of $M$. edulis to support the natural process is being developed in several regions of the world. The process of domestication of mussels will be aided by the development of genetic linkage maps (Lallias et al. 2007) and such maps need strengthening and improving by the addition of codominant markers like microsatellites. It will be interesting to see if the pair of loci (Med 362 and Med 722) that showed some evidence of linkage (significant deviation from linkage equilibrium), when mapped, will be close together in the same linkage group.

\section{ACKNOWLEDGMENTS}

The authors thank Niklas Tysklind for advice concerning the use of universal fluorescent-labeled tailed primers and Nicolas Bierne for helpful comments on an earlier version of this manuscript. This research has been financed by the European Regional Development Fund INTERREG IIIB Priority C, project 201 - AAAG2 (Atlantic Arc Aquaculture Group 2).

\section{LITERATURE CITED}

Beaumont, A. R., M. P. Hawkins, F. L. Doig, I. M. Davies \& M. Snow. 2008. Three species of Mytilus and their hybrids identified in a Scottish Loch: natives, relicts and invaders? J. Exp. Mar. Biol. Ecol. 367:100-110

Beaumont, A. R., M. Truebano Garcia, S. D. Hönig \& P. Low. 2006. Genetic variation amongst Scottish populations of the native oyster, Ostrea edulis, in relation to human-mediated gene flow. Aquat. Living Resour. 19:389-402.

Bierne, N., F. Bonhomme \& P. David. 2003a. Genetics at larval stage in marine bivalves. In: M. Fingerman \& R. Nagabhushanam, editors. Recent advances in marine biotechnology. Vol. 10. Enfield, New Hampshire: Science Publishers. pp. 239-262.

Bierne, N., P. Borsa, C. Daguin, D. Jollivet, F. Viard, F. Bonhomme \& P. David. 2003b. Introgression patterns in the mosaic hybrid zone between Mytilus edulis and M. galloprovincialis. Mol. Ecol. 12:447461.

Bierne, N., C. Daguin, F. Bonhomme, P. David \& P. Borsa. 2003c. Direct selection on allozymes is not required to explain heterogeneity among marker loci across a Mytilus hybrid zone. Mol. Ecol. 12:2505-2510.

Borsa, P., C. Daguin \& N. Bierne. 2007. Genomic reticulation indicates mixed ancestry in Southern-Hemisphere Mytilus spp. mussels. Biol. J. Linn. Soc. 92:747-754.

Boudry, P., C. Collet, F. Cornette, V. Hervouet \& F. Bonhomme. 2002. High variance in reproductive success of the Pacific oyster (Crassostrea gigas Thunberg) revealed by microsatellite-based parentage analysis of multifactorial crosses. Aquaculture 204:283-296.

Chapuis, M. P. \& A. Estoup. 2007. Microsatellite null alleles and estimation of population differentiation. Mol. Ecol. Evol. 24:621631.

Diz, A. P. \& P. Presa. 2008. Regional patterns of microsatellite variation in Mytilus galloprovincialis from the Iberian Peninsula. Mar. Biol. 154:277-286.

FAO Fisheries Department FI, Data and Statistics Unit (2006) FISHSTAT Plus: Universal software for fishery statistical time series. Version 2.3. 2000.
Faure, M. F., P. David, F. Bonhomme \& N. Bierne. 2008. Genetic hitchhiking in a subdivided population of Mytilus edulis. BMC Evol. Biol. 8:164.

Gaffney, P. M. 1994. Heterosis and heterozygote deficiencies in marine bivalves: more light? In: A. R. Beaumont, editor. Genetics and evolution of aquatic organisms. London: Chapman and Hall. pp. $146-153$.

Gardeström, J., R. T. Pereyra \& C. André. 2008. Characterization of six microsatellite loci in the Baltic blue mussel Mytilus trossulus and cross-species amplification in North Sea Mytilus edulis. Conserv. Genet. 9:1003-1005.

Gautschi, B., A. Widmer \& J. Koella. 2000. Isolation and characterization of microsatellite loci in the dice snake (Natrix tessellata). Mol. Ecol. 9:2191-2193.

Gérard, K., N. Bierne, P. Borsad, A. Chenuil \& J. P. Féral. 2008. Pleistocene separation of mitochondrial lineages of Mytilus spp. mussels from Northern and Southern Hemispheres and strong genetic differentiation among southern populations. Mol. Phylogenet. Evol. 49:84-91.

Gosling, E. M. 1992. The Mussel Mytilus: Ecology, Physiology, Genetics and Culture. Elsevier, Amsterdam.

Gosling, E. M., S. Doherty \& N. Howley. 2008. Genetic characterization of hybrid mussel (Mytilus) populations on Irish coasts. J. Mar. Biol. Ass. U.K. 88:341-346.

Hamilton, M. B., E. L. Pincus, A. Di Fiore \& R. C. Fleischer. 1999 Universal linker and ligation procedures for construction of genomic DNA libraries enriched for microsatellites. Biotechniques 27:500-507.

Heath, D. D., P. D. Rawson \& T. J. Hilbish. 1995. PCR-based nuclear markers identify alien blue mussel (Mytilus spp.) genotypes on the west coast of Canada. Can. J. Fish. Aquat. Sci. 52:26212627.

Hilbish, T. J., E. W. Carson, J. R. Plante, L. A. Weaver \& M. R. Gilg. 2002. Distribution of Mytilus edulis, M. galloprovincialis, and their hybrids in open-cost populations of mussels in south-western England. Mar. Biol. 140:137-142. 
Hilbish, T. J., A. Mullinax, S. I. Dolven, A. Meyer, R. K. Koehn \& P. D. Rawson. 2000. Origin of the anti-tropical distribution pattern in marine mussels (Mytilus spp.): routes and timing of transequatorial migration. Mar. Biol. 136:69-77.

Inoue, K., H. Waite, M. Matsuoka, S. Odo \& S. Harayama. 1995. Interspecific variations in adhesive protein sequences of Mytilus edulis, M. galloprovincialis, and M. trossulus. Biol. Bull. 189:370375.

Koehn, R. K. 1991. The genetics and taxonomy of species in the genus Mytilus. Aquaculture 94:125-145.

McDonald, J. H., R. Seed \& R. K. Koehn. 1991. Allozymes and morphometric characters of three species of Mytilus in the Northern and Southern Hemispheres. Mar. Biol. 111:323-333.

McGoldrick, D. J., D. Hedgecock, L. J. English, P. Baoprasertkul \& R. Ward. 2000. The transmission of microsatellite alleles in Australian and North American stocks of the Pacific oyster (Crassostrea gigas): selection and null alleles. J. Shellfish Res. 19:779-786.

Lallias, D., S. Lapègue, C. Hecquet, P. Boudry \& A. R. Beaumont. 2007. AFLP-based genetic linkage maps of the blue mussel (Mytilus edulis). Anim. Genet. 38:340-349.

Launey, S., C. Ledu, P. Boudry, F. Bonhomme \& Y. Naciri-Graven. 2002. Geographic structure in the European flat oyster (Ostrea edulis L.) as revealed by microsatellite polymorphisms. J. Hered. 93:331351.

Li, G., S. Hubert, K. Bucklin, V. Ribes \& D. Hedgecock. 2003. Characterization of 79 microsatellite markers in the Pacific oyster Crassostrea gigas. Mol. Ecol. Notes 3:228-232.

Presa, P., M. Pérez \& A. P. Diz. 2002. Polymorphic microsatellite markers for blue mussels (Mytilus spp.). Conserv. Genet. 3:441-443.
Rawson, P. D., S. Hayhurst \& B. Vanscoyoc. 2001. Species composition of blue mussel populations in the northeastern gulf of Maine. $J$. Shellfish Res. 20:31-38.

Rawson, P. D., K. Joyner \& T. J. Hilbish. 1996. Evidence for intragenic recombination with a novel genetic marker that distinguishes mussels in the Mytilus edulis species complex. Heredity 77:599-607.

Riginos, C. \& C. W. Cunningham. 2005. Local adaptation and species segregation in two mussel (Mytilus edulis x Mytilus trossulus) hybrid zones. Mol. Ecol. 14:381-400.

Rousset, F. \& M. Raymond. 1995. Testing heterozygote excess and deficiency. Genetics 140:1413-1419.

Schuelke, M. 2000. An economic method for the fluorescent labeling of PCR fragments. Nat. Biotechnol. 18:233-234.

Skibinski, D. O. F., J. A. Beardmore \& T. F. Cross. 1983. Aspects of the population genetics of Mytilus (Mytilidae; molluscs) in the British Isles. Biol. J. Linn. Soc. 19:137-183.

Spencer, B. E. 2002. Molluscan shellfish farming. Fishing news books, Oxford: Blackwell Science, 274 pp.

Van Oosterhout, C., W. F. Hutchinson, D. P. M. Wills \& P. Shipley. 2004. MICRO-CHECKER: software for identifying and correcting genotyping errors in microsatellite data. Mol. Ecol. Notes 4:535-538.

Varela, M. A., A. González-Tizón, L. Mariñas \& A. Martínez-Lage. 2007. Genetic divergence detected by ISSR markers and characterization of microsatellite regions in Mytilus mussels. Biochem. Genet. 45:565-578.

Vermeij, G. J. 1991. Anatomy of an invasion: the trans-Arctic interchange. Paleobiol. 17:281-307.

Yu, H. \& Q. I. Li. 2007. Development of EST-SSRs in the Mediterranean blue mussel, Mytilus galloprovincialis. Mol. Ecol. Notes 7:1308-1310. 